\title{
Optimal Taxation in the Solow-Uzawa Growth Model with Public Goods
}

\author{
Wei-Bin Zhang \\ Ritsumeikan Asia Pacific University, Japan \\ wbz1@apu.ac.jp
}

\begin{abstract}
This paper makes an original contribution to the literature of optimal taxation by introducing Ramsey taxation to the Solow-Uzawa growth model to examine genuine dynamic interdependence between growth and optimal taxation. We introduce a public sector to the Uzawa two-sector growth model. The public sector supplies public goods and services. The government financially supports by the public sector by collecting taxes on the household's wage income and wealth income under the assumption that the utility level is maximized. We derive the optimal taxation rule and construct the dynamics of the national economy. The model studies a nonlinear dynamics between national and sectoral growth, economic structural change, wealth/capital accumulation, and optimal tax rates in perfect competitive markets with the government intervention. The model has a unique stable equilibrium point with the chosen parameter values. We carry out comparative dynamic analysis to analyze effects of exogenous changes in a few parameters on the transitional process and long-term economic structure of the economic dynamics.
\end{abstract}

Keywords: Optimal taxation; tax rates; Uzawa's growth model; public good; growth.

\section{Introduction}

Since the pioneering work on optimal taxation by Ramsey (1927), how to formally analyze optimal taxation in different economies under different institutions has caused great attention from economists. The government may own and control the entire economy like in planning economies and can tax on almost any aspect of economic activities such as production activities, different incomes, and properties like in most of contemporary market economies. The emergence of extensive public invention in last few decades in the traditional market economies has stimulated many studies of taxation in the literature of theoretical as well as empirical economics. Different models in optimal tax theory focus various feasible taxes for the government. The government uses various objectives to evaluate various tax configurations. As taxation involves so many aspects in social and economic systems, it is reasonable to expect different approaches and various conclusions in the literature of optimal tax theory (e.g., Diamond and Mirrlees, 1971a, 1971b; Auerbach, 1985; Zodrow and Mieszkowski, 1986; Stiglitz, 1987; Wildasin, 1988; Slemrod, 1990; Wilson and Gordon, 2003; Lai, 2019). Irrespective of the extensive efforts over years, one of key aspects of optimal taxation is still poorly addressed in the literature. The theory has been mostly limited to static equilibrium framework. It is obvious that taxation should be studied in genuine dynamic framework. The contribution of this study is to introduce optimal taxation into the well-known Solow-Uzawa growth model, a core model in formal economic growth theory. This paper is concerned with dynamic inter-dependence between economic growth and optimal taxation. We address issues related to optimal taxation in neoclassical growth theory. We introduce a public sector to the Solow-Uzawa growth model (Solow, 1956; Uzawa, 1961).

The public sector supplies public goods and services and is financed by the government. The government collects taxes on the household's wage income and wealth income under the assumption that the utility level is maximized. We derive the optimal taxation rule and construct the dynamics of the national economy. The model studies a nonlinear dynamic interdependence between national and sectoral growth, economic structural change, wealth/capital accumulation, and optimal tax rates in perfect competitive markets with the government intervention. In almost all the recent literature of theoretical economics on dynamic interdependence of economic growth and optimal taxation economists apply either the OLG modeling framework in discrete time or the Ramsey framework in continuous time. Deviating from these theoretical approaches to studying household behavior, this study applies Zhang's approach to household behavior to analyze problems well-addressed in optimal taxation theory. Zhang's alternative approach was initially proposed in the early 1990s (Zhang, 1993). Zhang shows many implications of the modeling framework. In particular, the approach has similar implications to those of the well-known Keynesian consumption function and the permanent income hypothesis. It is known that the Keynesian approach and permanent income hypothesis are more empirically valid than the constant saving rate assumption in the Solow model and the in the Ramsey approach in describing household behavior. 
The approach is further referred to Zhang $(2005,2008)$. The rest paper is organized as follows. In section 2 we develop the basic model with public goods and optimal taxation. In section 3 we study how to solve the dynamics and simulate the motion of the national economy.

\section{The Solow-Uzawa Model with Optimal Taxation}

We base the model in this study the main features of Solow's growth model (Solow, 1956), Uzawa's two-sector growth model (Uzawa, 1961), and Zhang's model with endogenous growth and public goods (Zhang, 2016). In section 5 we conclude the study. Section 4 conducts comparative dynamic analysis to analyze effects of changes on the economic system over time with regards in some parameters. The appendix proves the main results in Section 3. We deviate from Zhang's model in that this study treats tax rates as endogenous variables, while they are parameters in Zhang's model. The household decision is based on Zhang's approach (Zhang, 1993, 2005). Like the Uzawa model, the economy has two private sectors, the capital goods sector producing capital goods and the consumer goods sector supplying consumer goods and services. The private sectors are characterized by perfect competition. The two-sector growth model is extended by including a public sector. The new sector supplies public goods with capital and labor as factor inputs. The public sector is financially by the government. The government taxes the households. We don't consider possible taxes on producers and impact of public goods on production of the private sectors. We use capital goods as unit of measurement and the price of capital goods is unity. Depreciation rate of capital goods is constant $\delta_{k}$, free mobility of capital and labor between the sectors is assumed. The households own assets. There is a fixed homogenous population. Let subscript index, $i, s$, and $p$, to denote respectively the capital goods, consumer goods, and public goods sectors. Let $K_{j}(t)$ and $N_{j}(t)$ stand for the capital stocks and labor force employed by sector $j, j=i, s, p$, at time $t$. We use $F_{j}(t)$ to denote the output level of sector $j$. Let $h$ stand for human capital.

The Capital Goods Sector: The production function of the capital goods sector is given by:

$F_{i}(t)=A_{i} K_{i}^{\alpha_{i}}(t) N_{i}^{\beta_{i}}(t), \alpha_{i}, \beta_{i}>0, \alpha_{i}+\beta_{i}=1$,

Where $A_{i}, \alpha_{i}$, and $\beta_{i}$ are parameters. We use $w(t)$ and $r(t)$ to stand for the wage rate and rate of interest.

As markets are perfectly competitive, labor and capital are paid by their marginal products. No firm earns positive profit. The profit is:

$\pi_{i}(t)=F_{i}(t)-\left(r(t)+\delta_{k}\right) r(t)-w(t) N_{i}(t)$.

The first-order conditions for maximizing the profit implies

$r_{\delta}(t)=\alpha_{i} A_{i} k_{i}^{-\beta_{i}}(t), w(t)=\beta_{i} A_{i} k_{i}^{\alpha_{i}}(t)$, (2)

Where $k_{i}(t) \equiv K_{i}(t) / N_{i}(t)$ and $r_{\delta}(t) \equiv r(t)+\delta_{k}$.

Service Sector: The service sector's technology is described by the following production function:

$F_{s}(t)=A_{s} K_{s}^{\alpha_{s}}(t) N_{s}^{\beta_{s}}(t), \alpha_{s}, \beta_{s}>0, \alpha_{s}+\beta_{s}=1,1>\theta_{s} \geq 0$, (3)

Where $\alpha_{s}$ and $\beta_{s}$ are parameters. The first-order conditions for maximizing the service sector's profit are:

$r_{\delta}(t)=\alpha_{s} A_{s} p(t) k_{s}^{-\beta_{s}}(t), w(t)=\beta_{s} A_{s} p(t) k_{s}^{\alpha_{s}}(t)$, (4)

Where $k_{s}(t) \equiv K_{s}(t) / N_{s}(t)$.

The Public Sector: We now study the public sector. This study assumes that the government finances the public sector. The public sector employs capital and workers, paying them at the same rates that the other two sectors pay. It is assumed that resources are effectively employed by the public sector. The effectiveness implies that the government budget is used in such a way that public services are optimized. Let $K_{p}(t)$ and $N_{p}(t)$ stand for, respectively capital stocks and labor force employed by the public sector. We specify the following supply function of public services:

$F_{p}(t)=A_{p} K_{p}^{\alpha_{0 p}}(t) N_{p}^{\beta_{0 p}}(t), \alpha_{0 p}, \beta_{0 p}, A_{p}>0$. (5)

The budget for the public sector is:

$w(t) N_{p}(t)+r_{\delta}(t) K_{p}(t)=Y_{p}(t)$

The first-order condition for optimizing public services under (6) implies: 
$r_{\delta}(t) K_{p}(t)=\alpha_{p} Y_{p}(t), w(t) N_{p}(t)=\beta_{p} Y_{p}(t)$

In which, $\alpha_{p} \equiv \frac{\alpha_{0 p}}{\alpha_{0 p}+\beta_{0 p}}, \quad \beta_{p} \equiv \frac{\beta_{0 p}}{\alpha_{0 p}+\beta_{0 p}}$.

Behavior of Households: We apply an alternative approach in describing behavior of households. The approach was suggested by Zhang (1993) and is applied many economic problems (Zhang, 2005). We use $\bar{k}(t)$ to represent the value of wealth that the representative household owns. Let $\tau_{w}(t)$, and $\tau_{k}(t)$ represent the tax rates on the wage income and the interest income. We define new variables: $\bar{\tau}_{x}(t) \equiv 1-\tau_{x}(t)$. The current income is

$y(t)=\bar{\tau}_{k}(t) \mathrm{R}(t)+\bar{\tau}_{w}(t) h w(t),(8)$

Where $\mathrm{R}(t) \equiv r(t) \bar{k}(t)$ is the interest payment, and $w(t)$ the wage rate. The disposable income is defined by:

$\hat{y}(t)=y(t)+\bar{k}(t) \cdot(9)$

The household distributes the disposable income between saving and consumption. Inserting (8) in (9) implies:

$\hat{y}(t) \equiv\left(1+\bar{\tau}_{k}(t) r(t)\right) \bar{k}(t)+\bar{\tau}_{w}(t) h w(t)$. (10)

The household uses the total available budget to consume $c_{s}(t)$ and $c_{i}(t)$, and to make saving $s(t)$ : $p(t) c_{s}(t)+c_{i}(t)+s(t)=\hat{y}(t) \cdot(11)$

We assume that the household's utility level $U(t)$ is a function of public goods $F_{p}(t), c_{s}(t), c_{i}(t)$ and $s(t)$ as follows: $U(t)=\theta F_{p}^{d_{0}}(t) c_{s}^{\gamma_{0}}(t) c_{i}^{\xi_{0}}(t) s^{\lambda_{0}}(t), d_{0}, \gamma_{0}, \xi_{0}, \lambda_{0}>0$, (12)

In which the power parameters are the representative household's utility elasticities of the corresponding variables. We call $d_{0}, \gamma_{0}, \xi_{0}$, and $\lambda_{0}$ the propensities to consume public goods, to consume consumer goods, to consume capital goods, and to hold wealth. Maximizing $U(t)$ subject to (12) yields:

$c_{s}(t)=\frac{\gamma \hat{y}(t)}{p(t)}, \quad c_{i}(t)=\xi \hat{y}(t), \quad s(t)=\lambda \hat{y}(t)$,

Where

$\gamma \equiv \rho \gamma_{0}, \xi \equiv \rho \xi_{0}, \lambda \equiv \rho \lambda_{0}, \rho \equiv \frac{1}{\gamma_{0}+\xi_{0}+\lambda_{0}}$

According to the definition of $s(t)$, we get wealth accumulation as follows:

$\dot{\bar{k}}(t)=s(t)-\bar{k}(t)$. (14)

This means that the change in wealth equals the saving minus the dissaving.

The Tax Income: The tax income is from taxing the wealth income and wage income. We have:

$T_{p}(t)=\tau_{k}(t) \mathrm{R}(t) \bar{N}+h \tau_{w}(t) w(t) \bar{N}$. (15)

For simplicity of analysis, we assume that the government fixes the ratio of the tax rates as follows:

$\tau_{k}(t)=\omega \tau_{w}(t), \quad(16)$

Where $\omega$ is a constant parameter decided by the government?

The Government Determines the Tax Rates: The government is assumed to determine the tax rates in order to maximize the utility function. By (12) and (13):

$U(t)=\frac{\theta \gamma^{\gamma_{0}} \xi^{\xi_{0}} \lambda^{\lambda_{0}}}{p^{\gamma_{0}}(t)} F_{p}^{d_{0}}(t) \hat{y}^{1 / \rho}(t)$

From (9) and (7), we have:

$F_{p}(t)=A_{p}\left(\frac{\alpha_{p}}{r_{\delta}(t)}\right)^{\alpha_{0 p}}\left(\frac{\beta_{p}}{w(t)}\right)^{\beta_{0 p}} Y_{p}^{\alpha_{0 p}+\beta_{0 p}}(t)$.

Insert (18) in (17): $U(t)=u(t) Y_{p}^{d}(t) \hat{y}^{1 / \rho}(t)$, (19)

Where

$u(t) \equiv A_{p}^{d_{0}}\left(\frac{\alpha_{p}}{r_{\delta}(t)}\right)^{d_{0} \alpha_{0 p}}\left(\frac{\beta_{p}}{w(t)}\right)^{d_{0} \beta_{0 p}} \frac{\theta \gamma^{\gamma_{0}} \xi^{\xi_{0}} \lambda^{\lambda_{0}}}{p^{\gamma_{0}}(t)}, d \equiv\left(\alpha_{0 p}+\beta_{0 p}\right) d_{0}$.

As the income of the government from taxing is spent on supplying public goods, we have:

$Y_{p}(t)=T_{p}(t)=\tau_{k}(t) \mathrm{R}(t) \bar{N}+\tau_{w}(t) h w(t) \bar{N} .(20)$

By (10) and (20), we express $U(t)$ as a function of $\tau_{k}(t)$ and $\tau_{w}(t)$ as follows: 
$U(t)=u(t)\left(\tau_{k}(t) \mathrm{R}(t)+\tau_{w}(t) h w(t)\right)^{d} \bar{N}^{d} \hat{y}^{1 / \rho}(t) .(21)$

Maximizing $U(t)$ by taking derivatives of the utility function, respectively, in $\tau_{k}(t)$ and $\tau_{w}(t)$, we have a single marginal condition:

$\frac{\tau_{k}(t) \mathrm{R}(t)+\tau_{w}(t) h w(t)}{\hat{y}(t)}=\frac{Y_{P}(t) / \bar{N}}{\hat{y}(t)}=d \rho$.

The rule implies that the ratio between the tax income and the disposable income is a constant $d \rho$. By (10), we have, $\hat{y}(t)=y_{0}(t)-\frac{Y_{P}(t)}{\bar{N}}$,

Where $y_{0}(t) \equiv(1+r(t)) \bar{k}(t)+h w(t)$. From (22) and (23), we have

$\frac{Y_{P}(t)}{\bar{N}}=\frac{d \rho y_{0}(t)}{1+d \rho}$.

Equation (24) implies that the government's optimal tax policy per capita is proportional to the disposable income when the tax rates are zero. It should be noted that in the literature of optimal taxation, the Ramsey rule is well-known. Ramsey considers an economy with a single consumer. The government determines commodity taxes to maximize the utility of the consumer under the condition that the tax income is to cover a required level of tax revenue. The Ramsey rule implies that the optimal taxes make every good to change in the same proportional reduction in compensated demand (e.g., Ramsey, 1927; Mas-Colell, et al., 1995). Our problem differs from the Rumsey one mainly in that we maximize the utility without fixing government's tax revenue. Moreover, we are concerned with taxes on wage and capital income.

Equilibrium Conditions for Consumer Goods and Capital Goods: The equilibrium condition in consumer goods market implies:

$c_{s}(t) \bar{N}=F_{S}(t)$. (25)

The equilibrium condition in capital goods market implies:

$c_{i}(t) \bar{N}+s(t) \bar{N}+\delta_{k} K(t)=F_{i}(t)+K(t)$.

This equation can be equally written as:

$\dot{K}(t)=F_{i}(t)-c_{i}(t) \bar{N}-\delta_{k} K(t) . \quad(26)$

This equation states that the capital stock change is capital goods produced minus the capital depreciated and capital goods consumed.

Full Employment of Capital and Labor: The national capital stock $K(t)$ is employed by the three sectors. Labor and capital are fully employed:

$K_{i}(t)+K_{s}(t)+K_{p}(t)=K(t)$

$N_{i}(t)+N_{s}(t)+N_{p}(t)=h \bar{N}$. (28)

The national wealth is owned by the households. We thus have:

$K(t)=\bar{k}(t) \bar{N}$. (29)

We built the dynamic growth model with three sectors. It is an extension of the Solow-Uzawa two-sector growth model basing on the literature of optimal taxation.

\section{The Dynamics of the Economy}

In the appendix it is shown that the movement of the national economic dynamics is described by one differential equation with $z(t)$ as the variable, where $z(t) \equiv w(t) /\left(r(t)+\delta_{k}\right)$. The following lemma gives a way to describe the economic dynamics.

Lemma: The following differential equation describes motion of $z(t)$ :

$\dot{\bar{k}}(t)=\widetilde{\Psi}(z(t)),(30)$

In which $\widetilde{\Psi}$ is a function of $z(t)$ given in the Appendix. We determine all the other variables as functions of $z(t)$ by following calculating order: $\bar{k}(t)$ by (A13) $\rightarrow r(t)$ and $w(t)$ by (A2) $\rightarrow r_{\delta}(t)=r(t)-\delta_{k} \rightarrow$ $\tau_{w}(t) \rightarrow \tau_{k}(t)$ by (16) $\rightarrow y_{0}(t)$ by definition $\rightarrow K_{s}(t)$ by (A9) $\rightarrow K(t)=\bar{k}(t) \bar{N} \rightarrow K_{i}(t)$ by (A5) $\rightarrow K_{p}(t)$ 
by (A5) $\rightarrow k_{j}(t)=z(t) / \bar{\alpha}_{j}, j=i, s, p \rightarrow N_{j}(t)=K_{j}(t) / k_{j}(t) \rightarrow F_{j}(t)$ by the specified forms $\rightarrow U(t)$ by $(19) \rightarrow p(t)$ by (A3) $\rightarrow \hat{y}(t)$ by (A6) $\rightarrow c_{s}(t), c_{i}(t)$ and $s(t)$ by (13) $\rightarrow T_{p}(t)$ by (15) $\rightarrow Y_{p}(t)=T_{p}(t)$.

By the Lemma we can follow the economic dynamics. We specify parameter values as follows:

$\bar{N}=100, \alpha_{i}=0.3, \alpha_{s}=0.35, \alpha_{0 p}=0.3, \beta_{0 p}=0.5, A_{i}=1.1, A_{s}=0.9, A_{p}=0.9, \lambda_{0}=0.8$, $\xi_{0}=0.1, \gamma_{0}=0.06, \theta=1, \omega=1, h=4, d_{0}=0.05, \delta_{k}=0.03$. (31)

The population is 100 . We fix the propensity to save at 0.8 . The propensity to consume goods is 0.1 . The propensity to consume services is lower than the propensity to consume goods. The propensity to consume public goods is 0.05 . The ratio of the tax rates 1 , which implies that the government taxes the wage income and the wealth income with the same rate. We fix the elasticities of capital in the Cobb-Douglas production functions near 0.3. The parameter values are not referred to a given economy. We consider this acceptable as our main purpose of providing insights into the movement of the economic system will not be affected. We choose the initial condition: $z(0)=14$.3. Figure 1 plots the motion of the economic dynamics. The tax rates rise slightly over time. In the figure the variable $Y(t)$ stands for the GDP defined as follow: $Y(t)=r(t) K(t)+w(t) h \bar{N}$. The GDP and tax income rise over time. The three sectors change slightly. The rate of interest falls. The wage rate rises over time. The changes of the other variables are plotted in Figure 1.

Full Employment of Capital and Labor: The national capital stock $K(t)$ is employed by the three sectors. The full employment of labor and capital is represented by:

$K_{i}(t)+K_{s}(t)+K_{p}(t)=K(t), \quad(27)$

$N_{i}(t)+N_{s}(t)+N_{p}(t)=h \bar{N}$. (28)

The national wealth is owned by the households. We thus have:

$K(t)=\bar{k}(t) \bar{N}$. (29). We built the dynamic growth model with three sectors.

\section{Figure 1: The Motion of the Economic System}
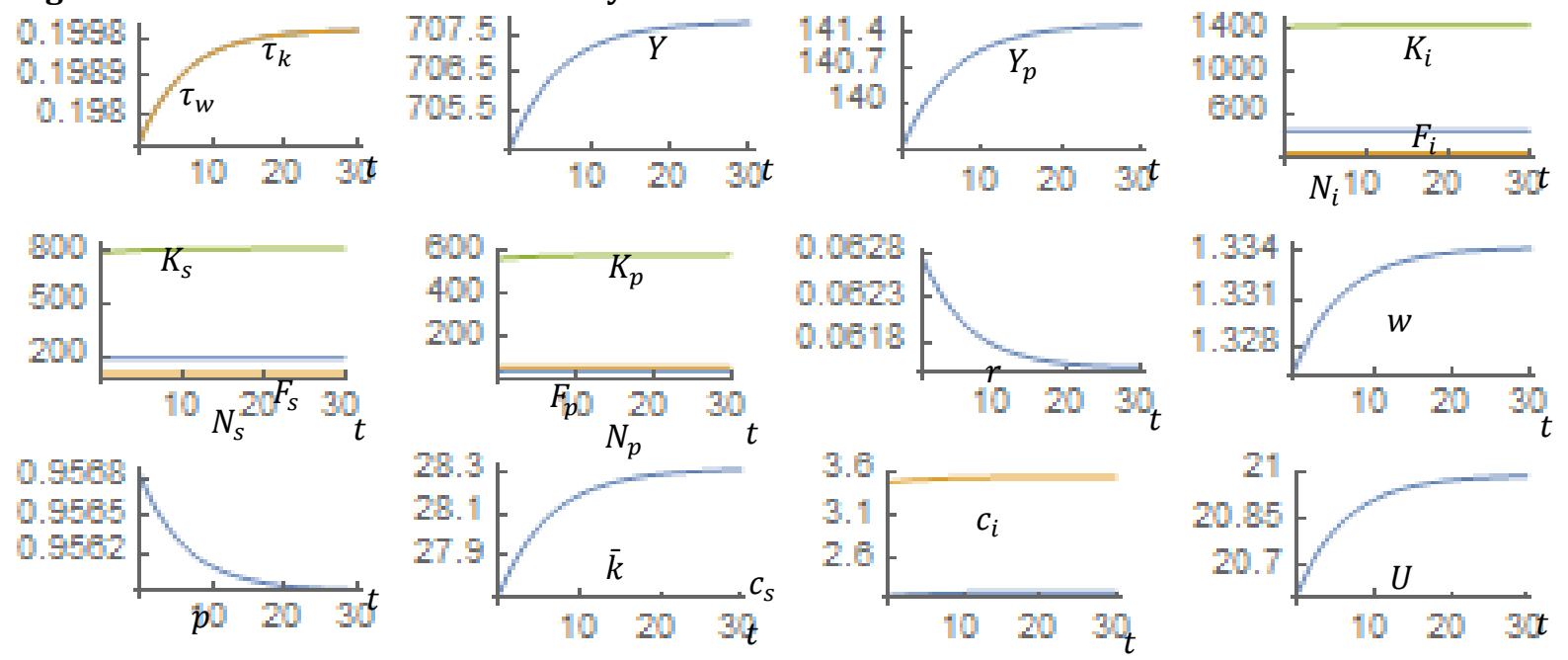

We calculate the equilibrium values as follows:

$\tau_{w}=\tau_{w}=0.2, Y=707.8, Y_{p}=141.6, r=0.062, p=0.96, w=1.33, F_{i}=438.9, F_{s}$ $=191.5$,

$F_{p}=49.4, N_{i}=230.2, \quad N_{s}=103.5, \quad N_{p}=66.3, \quad K_{i}=1438.9, K_{s}=812.3, K_{p}=580.2, \bar{k}=28.3$,

$c_{i}=2.54, c_{s}=2.22, U=21$. (32)

The eigenvalue of the unique equilibrium point is -0.156 . The negative eigenvalue implies the stability of equilibrium point. This guarantees that we can effectively conduct comparative dynamic analysis. 


\section{Comparative Dynamic Analysis}

The previous section simulates the movement of the economic system. The simulation procedure implies that it is straightforward to study how parameter changes have effects on the movement of the system with conduct comparative dynamic analysis. A variable $\bar{\Delta} x(t)$ is defined to represent for the change rate of the variable $x(t)$ in percentage due to changes in the parameter value.

A Rise in the Utility Elasticity for Public Goods: We first examine how the economic dynamics is affected by the following rise in the utility elasticity for public goods: $d_{0}=0.05$ to 0.055 . Figure 2 plots the simulation result. Intuitively we see that as the utility level is enhanced with the same level of public goods, the government can enhance the households' welfare by increasing more public goods if the other variables in the utility function not much reduced. The government reacts the rise in the utility elasticity of public goods by increasing the tax rates, resulting in the expansion of the public goods sector. The tax income is increased. The GDP rises initially and falls slightly in the long term. The higher tax rates result in falling in the household's wealth, consumption of goods and services. The rate of interest is enhanced. The wage rate is reduced. The scales of the two private sectors are shrunk. The price of services is reduced. We see that a rise in the utility elasticity in public goods discourages the development of private sectors by absorbing more resources from the economy. The benefit from the increased public goods will not benefit the national economy in terms of the utility level and the GDP.

Figure 2: A Rise in the Utility Elasticity for Public Goods
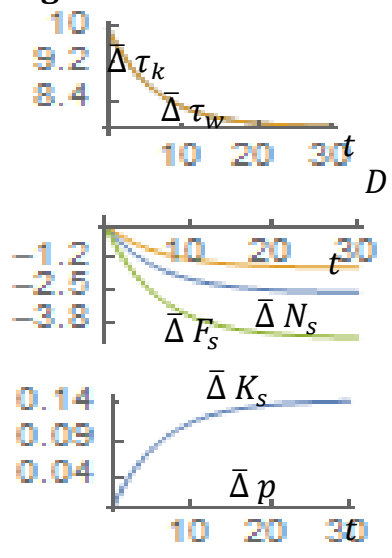
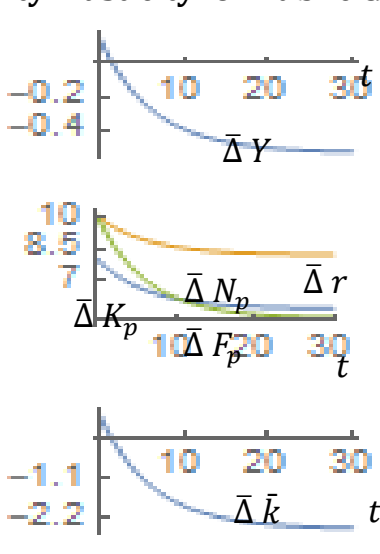
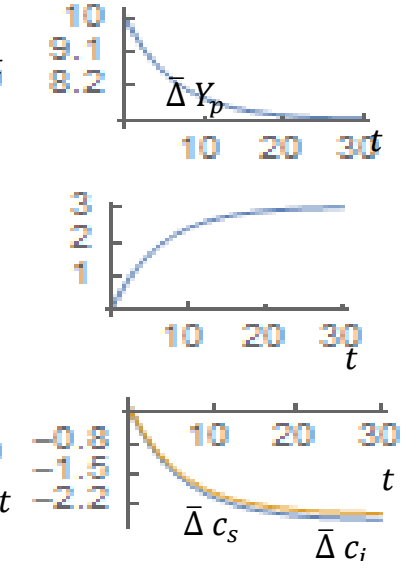
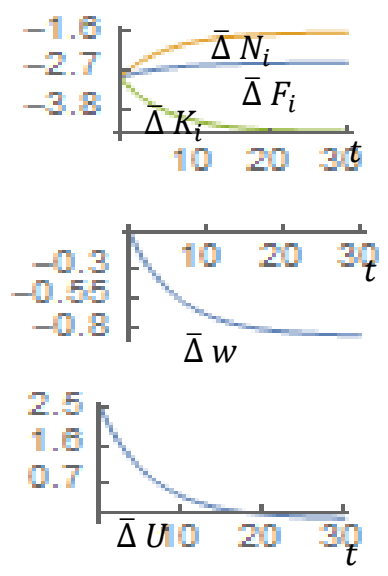

The Capital Goods Sector Increases its Productivity: We now study the transitory and long-term effects of the following improvement in the capital goods sector's total factor productivity: $A_{i}=1.1$ to 1.15 . Figure 3 plots the simulation result. As its productivity is enhanced, the capital goods sector is expanded. The sector produces more and employs more capital. The labor force employed by the capital goods sector is increased initially but is not changed in the long term. The labor force distribution is not affected in the long term. The tax rates are initially reduced but are not affected in the long term. The public sector initially employs less capital and labor force and produces less, employs more capital and produce more in the long term. The consumer goods sector initially employs less capital and labor force and produces less, employs more capital and produce more in the long term. The rate of interest is initially enhanced and is not affected in the long term. The wage rate is enhanced. The price of services is increased. The representative household has more wealth and consumes more capital goods. The household consumes less consumer goods initially but more in the long term. 
Figure 3: The Capital Goods Sector Increases its Total Factor Productivity
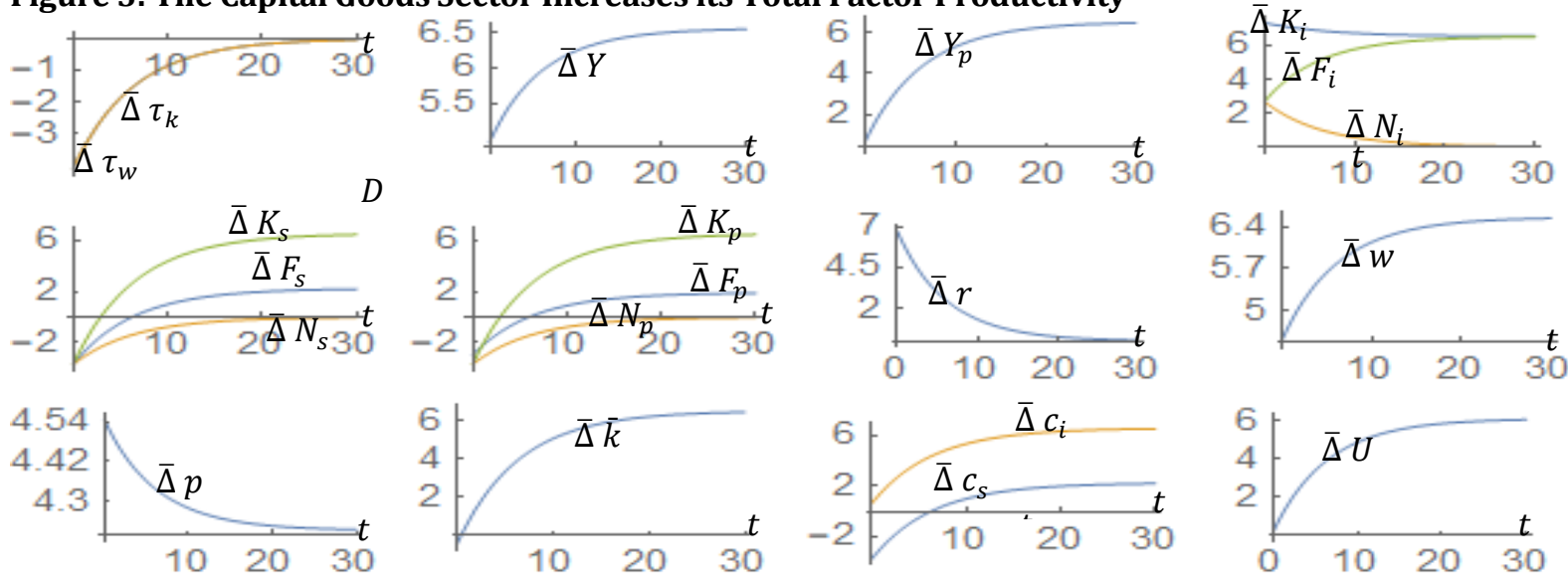

A Rise in the Public Goods Output Elasticity of Labor Force: We now analyze what happen to the economic dynamics if the public goods output elasticity of labor force is increased as follows: $\alpha_{0 p}=0.3$ to 0.32 . Figure 4 plots the simulation result. The public sector employs more labor force initially and employs the same number of workers in the long term. The utility level is increased. The public sector expands the scale and employs more capitals. The tax rates are increased. The GDP rises initially but falls in the long term. The capital goods sector is shrunk. The consumer goods sector is expanded initially but shrunk in the long term. The rate of interest is increased. The wage rate is reduced. The labor distribution reminds invariant in the long term. The price of services is increased. The representative household has more wealth initially but less in the long term. The household consumes more capital goods and consumer goods initially but less in the long term.

Figure 4: A Rise in the Public Goods Output Elasticity of Labor Force
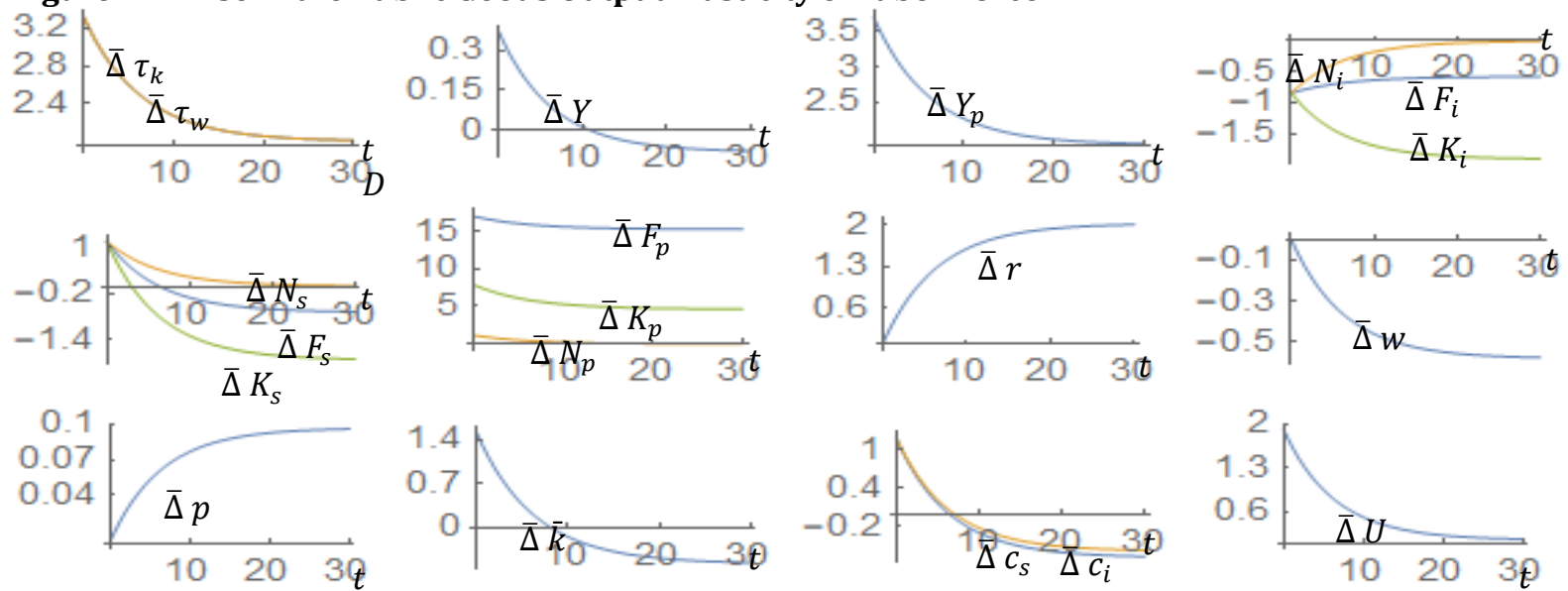

The Propensity to Save is Increased: We now study the case when the propensity to save is augmented as follows: $\lambda_{0}=0.8$ to 0.82 . Figure 5 plots the simulation result. The representative household's wealth is increased. The household consumes less capital goods and consumer goods, but more in the long term. The tax rates are reduced initially and are not affected in the long term. The public sector supplies more public goods and employs more capital and labor force. The consumer goods sector employs less labor force. The capital goods sector employs more labor force initially but less in the long term. The GDP and utility level are increased. The rate of interest is reduced. The wage rate is enhanced. The price of consumer goods is decreased. The two private sectors are expanded in the long term. 
Figure 5: The Propensity to Save is Increased
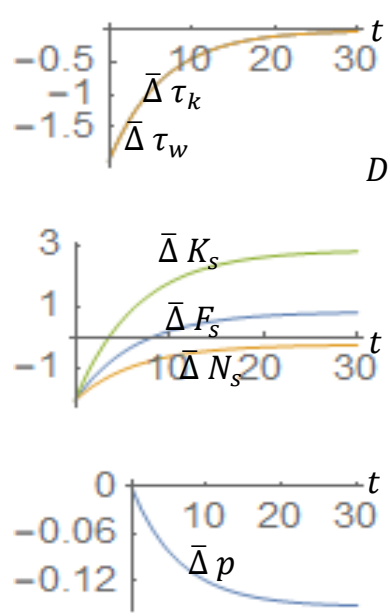
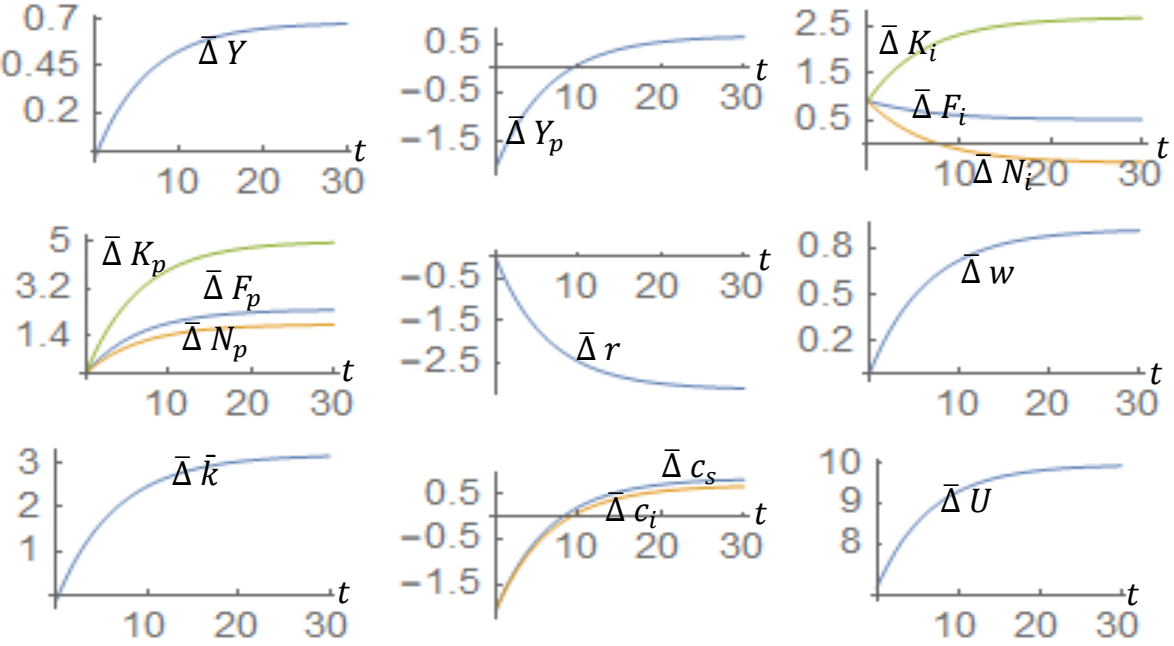

The Propensity to Consume Capital Goods is Increased: We now study the case that the propensity to consume capital goods is increased as follows: $\xi_{0}=0.1$ to 0.11 . Figure 6 plots the simulation result. The representative household's wealth is reduced. The household consumes more capital goods and less consumer goods. The tax rates are reduced. The public sector supplies less public goods and employs less capital and labor force. The consumer goods sector employs less labor force. The capital goods sector employs more labor force. The GDP is reduced. The utility level is increased initially but reduced in the long term. The rate of interest is augmented. The wage rate is reduced. The price of consumer goods is increased. The capital goods sector's output is increased. The consumer goods sector's output is reduced.

Figure 6: The Propensity to Consume Capital Goods is Increased
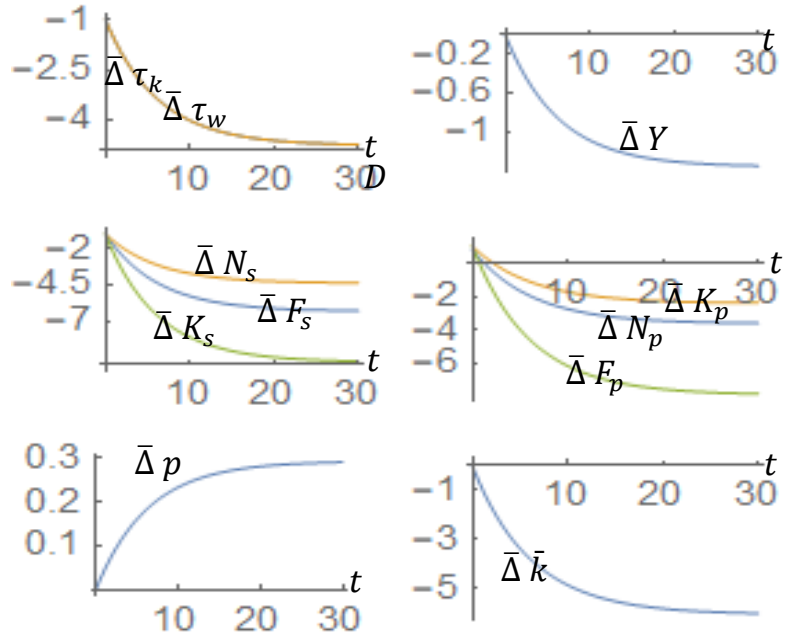
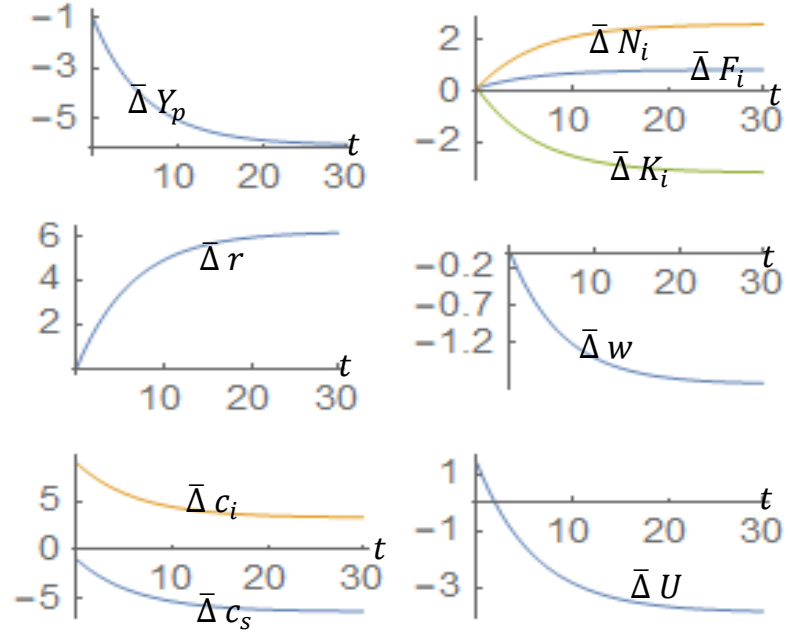

The Propensity to Consume Consumer Goods is Increased: We now analyze what happen to the economic system if the propensity to consume consumer goods is augmented as follows: $\gamma_{0}=0.06$ to 0.07 . Figure 7 plots the simulation result. The representative household's consumption level of consumer goods is increased. The consumer goods sector produces more and employs more input factors. The tax rates are reduced. The government has less tax income. The public sector supplies less public service and employs less input factors. The capital goods sector is shrunk. The GDP is reduced. The utility level is reduced. The rate of interest is augmented. The wage rate is reduced. The price of consumer goods is increased. The model studies a nonlinear dynamic interdependence between economic structure, wealth/capital, and optimal tax rates in perfect competitive markets. The model has a unique stable equilibrium point. The study focuses on effects of changes in 


\section{Journal of Social and Development Sciences (ISSN 2221-1152)}

Vol. 10, No. 3, pp. 1-10, September 2019

some parameters on the transitional processes and long-term economic structure of the economic dynamics. It should be noted that it is straightforward to conduct comparative dynamic analysis with other variables. It is also possible to get more insights from simulating other forms of production and utility functions.

Figure 7: The Propensity to Consume Consumer Goods is Increased
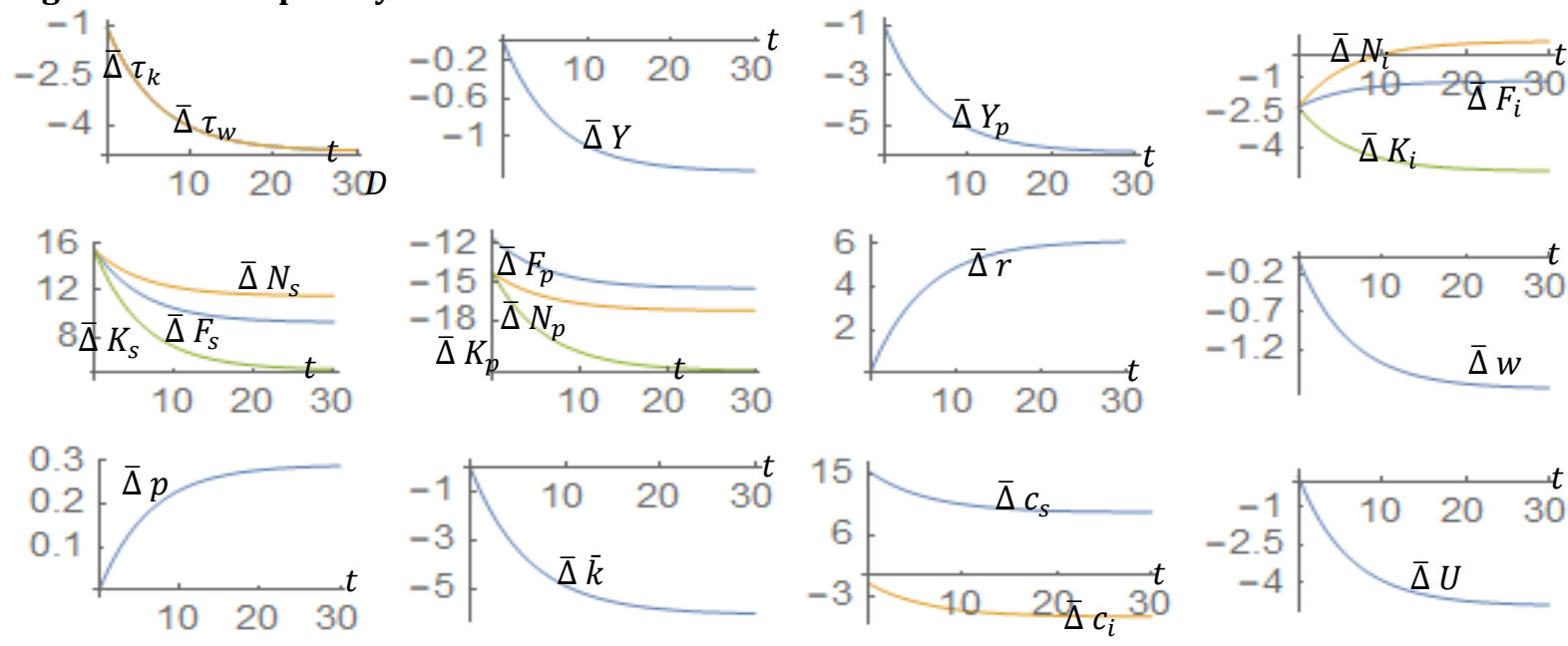

\section{Conclusion}

This paper analyzes dynamic inter-dependence between economic growth and optimal taxation. We introduced the public sector to the Uzawa two-sector growth model. The public sector supplies public goods and services and financially supported by taxation. Tax is collected from the household's wage income and wealth income under the assumption that the utility level is maximized. We derived the optimal taxation rule and constructed the dynamics of the national economy. We can also extend the model. Our model is based on the two most popular models, the Solow model and the Uzawa two-sector growth model, in the literature of neoclassical growth theory. We can learn many ideas for generalization (Burmeister and Dobell, 1970; Zhang, 2005). The literature of optimal taxation also points out many issues to be further examined. There is a large literature on the role of productive fiscal policy as on sustainable economic growth (Barro, 1990; Turnovsky, 2004; Gómez, 2008). There is an extensive literature on issues related to tax competition in interregional and national economic growth are (e.g., Wilson, 1986; Baldwin and Krugman, 2004; and Ihori and Yang, 2009). As our dynamic models are built in a general dynamic equilibrium framework with microeconomic foundation, it is conceptually not difficult to make extensions and generalizations of the model on basis of past literature on different aspects of taxation.

Appendix: We now check the Lemma. From (3), (6) and (9), we get:

$z \equiv \frac{w}{r_{\delta}}=\bar{\alpha}_{i} k_{i}=\bar{\alpha}_{s} k_{s}=\bar{\alpha}_{p} k_{p}$,

Where

$k_{j} \equiv \frac{K_{j}}{N_{j}}, \quad \bar{\alpha}_{j} \equiv \frac{\beta_{j}}{\alpha_{j}}, j=i, s, p$.

Insert (A1) in (3)

$r(z)=\alpha_{i} A_{i}\left(\frac{z}{\bar{\alpha}_{i}}\right)^{-\beta_{i}}-\delta_{k}, w(z)=z r_{\delta}$.

From (A1) and (4), we have

$p(z)=\frac{r_{\delta}}{\alpha_{s} A_{s}}\left(\frac{z}{\bar{\alpha}_{s}}\right)^{\beta_{s}}$.

Insert $k_{j}=z / \bar{\alpha}_{j}$ and $N_{j}=K_{j} / k_{j}$ in (28)

$\bar{\alpha}_{i} K_{i}+\bar{\alpha}_{s} K_{s}+\bar{\alpha}_{p} K_{p}=z h \bar{N}$. (A4)

From (A2) and $K_{i}=K-K_{s}-K_{p}$, we have

$K_{p}=\alpha_{x} z h \bar{N}-\alpha_{x} \bar{\alpha}_{i} K-\left(\bar{\alpha}_{s}-\bar{\alpha}_{i}\right) \alpha_{x} K_{s}$, 


\section{Journal of Social and Development Sciences (ISSN 2221-1152)}

\section{Vol. 10, No. 3, pp. 1-10, September 2019}

$K_{i}=K-K_{s}-K_{p},(A 5)$

Where $\alpha_{x} \equiv 1 /\left(\bar{\alpha}_{p}-\bar{\alpha}_{i}\right)$. From (14) and (25), we have

$\gamma \hat{y} \bar{N}=p F_{s}$. (A6)

Substituting $r_{\delta}=\alpha_{s} p F_{s} / K_{s}$ into (A6) yields:

$\gamma \hat{y} \bar{N}=\frac{r_{\delta} K_{s}}{\alpha_{s}}$. (A7)

By (22) and (24), we get

$\hat{y}=\frac{y_{0}}{1+d \rho}$. (A8)

Insert (A8) in (A7)

$K_{s}=\frac{\alpha_{s} \gamma \bar{N} y_{0}}{(1+d \rho) r_{\delta}}$.

By (3) (A9) and (A19), we have:

$F_{s}=A_{s} K_{s}\left(\frac{\bar{\alpha}_{s}}{Z}\right)^{\beta_{s}} \cdot(A 10)$

By (24), (16), and (20), we get

$\tau_{w}=\frac{d \rho y_{0}}{(1+d \rho)(\omega \mathrm{R}+h w)} .(A 11)$

Insert (A9), (29), and (7) in (A5)

$\tilde{R} y_{0}=h_{z}-\bar{\alpha}_{i} \bar{k},(A 12)$

in which we also use (24) and

$\tilde{R}(z) \equiv\left(\frac{d \rho \alpha_{p}}{\alpha_{x}}+\left(\bar{\alpha}_{s}-\bar{\alpha}_{i}\right) \alpha_{s} \gamma\right) \frac{1}{(1+d \rho) r_{\delta}}$.

From the definition of $y_{0}$ and (A12), we solve

$\bar{k}(z)=\frac{(z-w \tilde{R}) h}{(1+r) \tilde{R}+\bar{\alpha}_{i}}$.

We obtain the values of the variables as functions of $z$ with the following computational order: $\bar{k}$ by (A13) $\rightarrow$ $r$ and $w$ by (A2) $\rightarrow r_{\delta}=r-\delta_{k} \rightarrow \tau_{w} \rightarrow \tau_{k}$ by (16) $\rightarrow y_{0}$ by definition $\rightarrow K_{s}$ by (A9) $\rightarrow K=\bar{k} N \rightarrow K_{i}$ by (A5) $\rightarrow K_{p}$ by (A5) $\rightarrow k_{j}=z / \bar{\alpha}_{j}, j=i, s, p \rightarrow N_{j}=K_{j} / k_{j} \rightarrow F_{j}$ by (1), (3) and (5) $\rightarrow U$ by (19) $\rightarrow p$ by (A3) $\rightarrow \hat{y}$ by (A6) $\rightarrow c_{s}, c_{i}$ and $s$ by (13) $\rightarrow T_{p}$ by (15) $\rightarrow Y_{p}=T_{p}$. By (9), (14) and this procedure, we have

$\dot{\bar{k}}=\widetilde{\Psi}(\bar{k}) \equiv s-\bar{k} \cdot(A 14)$

The derivative of (A13) in time implies:

$\dot{\bar{k}}=\frac{\partial \bar{k}}{\partial z} \dot{z} \cdot(A 15)$

From (A14) and (A15), we have

$\dot{z}=\widetilde{\Psi}\left(\frac{\partial \bar{k}}{\partial z}\right)^{-1}$.

We thus proved the Lemma.

Acknowledgements: The author is thankful to the important comments of the anonymous referee.

\section{References}

Auerbach, A. J. (1985). The Theory of Excess Burden and Optimal Taxation. In Handbook of Public Economics, edited by Auerbach and Feldstein, 69-127.

Barro, R. J. (1990). Government Spending in a Simple Model of Endogenous Growth. Journal of Political Economy, 98(S5), S103-25.

Baldwin, R. E. \& Krugman, P. (2004). Agglomeration, Integration and Tax Harmonization. European Economic Review, 48(1), 1-23.

Burmeister, E. \& Dobell, A. R. (1970). Mathematical Theories of Economic Growth. London: Collier Macmillan Publishers. 
Diamond, P. \& Mirrlees, J. A. (1971a). Optimal Taxation and Public Production I: Production Efficiency. American Economic Review, 61(1), 8-27.

Diamond, P. \& Mirrlees, J. A. (1971b). Optimal Taxation and Public Production II: Tax Rules. American Economic Review, 61(3), 261-78.

Gómez, M. A. (2008). Fiscal Policy, Congestion, and Endogenous Growth. Journal of Public Economic Theory, $10(4), 595-622$.

Ihori, T. \& Yang, C. C. (2009). Interregional Tax Competition and Intraregional Political Competition: The Optimal Provision of Public Goods under Representative Democracy. Journal of Urban Economics, 66(3), 210-17.

Lai, Y. B. (2019). Environmental Policy Competition and Heterogeneous Capital Endowments. Regional Science and Urban Economics, 75(2019), 107-19.

Mas-Colell, A., Whinston, M. D. \& Green, J. R. (1995). Microeconomic Theory. Oxford: Oxford University Press.

Ramsey, F. (1927). A Contribution to the Theory of Taxation. Economic Theory, 37(145), 47-61.

Slemrod, J. (1990). Optimal Taxation and Optimal Tax Systems. Journal of Economic Perspectives 4(Winter), 157-78.

Solow, R. (1956). A Contribution to the Theory of Growth. Quarterly Journal of Economics, 70(1), 65-94.

Stiglitz, J. E. (1987). Pareto Efficient and Optimal Taxation and the New Welfare Economics. In Handbook of Public Economics 2, edited by Auerbach, A. and Feldstein, M, 991-1042.

Turnovsky, S. J. (2004). The Transitional Dynamics of Fiscal Policy: Long-Run Capital Accumulation and Growth. Journal of Money, Credit, and Banking, 36(5), 883-910.

Uzawa, H. (1961). On a Two-Sector Model of Economic Growth. Review of Economic Studies, 29(1), 47-70.

Wildasin, D. E. (1988). Nash Equilibria in Models of Fiscal Competition. Journal of Public Economics, 35(3), 229-40.

Wilson, J. D. (1986). A Theory of Interregional Tax Competition. Journal of Urban Economics, 19(3), 296-315.

Wilson, J. D. \& Gordon, R. (2003). Expenditure Competition. Journal of Public Economic Theory, 5(2), 499-417.

Zhang, W. B. (1993). Wages, Service Prices and Rent - Urban Division of Labor and Amenities. Seoul Journal of Economics, 6(1), 97-113.

Zhang, W. B. (2005). Economic Growth Theory. London: Ashgate.

Zhang, W. B. (2008). International Trade Theory: Capital, Knowledge, Economic Structure, Money and Prices over Time and Space. Berlin: Springer.

Zhang, W. B. (2016). Public Debt and Economic Growth in Uzawa's Two-Sector Model with Public Goods. International Journal of Economic Sciences, 5(4), 52-73.

Zodrow, G. R. \& Mieszkowski, P. (1986). Pigou, Tiebout, Property Taxation, and the Under-provision of Local Public Goods. Journal of Urban Economics, 19(3), 356-70. 